\title{
The impact of lockdown on pediatric ED visits and hospital admissions during the COVID19 pandemic: a multicenter analysis and review of the literature
}

\author{
Matthijs D. Kruizinga ${ }^{1,2}$ (D) Daphne Peeters ${ }^{1} \cdot$ Mirjam van Veen ${ }^{3} \cdot$ Marlies van Houten $^{4} \cdot$ Jantien Wieringa $^{5} \cdot$ \\ Jeroen G. Noordzij ${ }^{6}$. Jolita Bekhof ${ }^{7} \cdot$ Gerdien Tramper-Stranders $^{8} \cdot$ Nienke J. Vet $^{9} \cdot$ Gertjan J. A. Driessen $^{1,10}$
}

Received: 6 January 2021 / Revised: 25 February 2021 / Accepted: 4 March 2021 / Published online: 15 March 2021

(C) The Author(s) 2021

\begin{abstract}
The coronavirus disease 2019 pandemic has enormous impact on society and healthcare. Countries imposed lockdowns, which were followed by a reduction in care utilization. The aims of this study were to quantify the effects of lockdown on pediatric care in the Netherlands, to elucidate the cause of the observed reduction in pediatric emergency department (ED) visits and hospital admissions, and to summarize the literature regarding the effects of lockdown on pediatric care worldwide. ED visits and hospital admission data of 8 general hospitals in the Netherlands between January 2016 and June 2020 were summarized per diagnosis group (communicable infections, noncommunicable infections, (probable) infection-related, and noninfectious). The effects of lockdown were quantified with a linear mixed effects model. A literature review regarding the effect of lockdowns on pediatric clinical care was performed. In total, 126,198 ED visits and 47,648 admissions were registered in the study period. The estimated reduction in general pediatric care was 59\% and 56\% for ED visits and admissions, respectively. The largest reduction was observed for communicable infections (ED visits: 76\%; admissions: 77\%), whereas the reduction in noninfectious diagnoses was smaller (ED visits 36\%; admissions: 37\%). Similar reductions were reported worldwide, with decreases of 30-89\% for ED visits and $19-73 \%$ for admissions.
\end{abstract}

Matthijs D. Kruizinga and Daphne Peeters contributed equally to this work.

Communicated by Nicole Ritz

Matthijs D. Kruizinga

m.kruizinga@ hagaziekenhuis.nl

Daphne Peeters

d.peeters@hagaziekenhuis.nl

Mirjam van Veen

Mirjam.van.Veen@ghz.nl

Marlies van Houten

MvanHouten2@ spaarnegasthuis.nl

Jantien Wieringa

j.boltwieringa@haaglandenmc.nl

\author{
Jeroen G. Noordzij \\ j.noordzij@rdgg.nl \\ Jolita Bekhof \\ j.bekhof@isala.nl \\ Gerdien Tramper-Stranders \\ G.Tramper@franciscus.nl \\ Nienke J. Vet \\ n.vet@antoniusziekenhuis.nl \\ Gertjan J. A. Driessen \\ gertjan.driessen@mumc.nl
}

Extended author information available on the last page of the article 
Conclusion: Pediatric ED utilization and hospitalization during lockdown were decreased in the Netherlands and other countries, which can largely be attributed to a decrease in communicable infectious diseases. Care utilization for other conditions was decreased as well, which may indicate that care avoidance during a pandemic is significant.

What is Known:

- The COVID-19 pandemic had enormous impact on society.

- Countries imposed lockdowns to curb transmission rates, which were followed by a reduction in care utilization worldwide.

What is New:

- The Dutch lockdown caused a significant decrease in pediatric ED utilization and hospitalization, especially in ED visits and hospital admissions because of infections that were not caused by SARS-CoV-2.

- Care utilization for noninfectious diagnoses was decreased as well, which may indicate that pediatric care avoidance during a pandemic is significant.

Keywords COVID-19 $\cdot$ Corona $\cdot$ SARS-CoV-2 $\cdot$ Lockdown $\cdot$ Pediatrics $\cdot$ Admissions $\cdot$ ED visits

\section{Introduction}

In 2020, the world was shocked by the pandemic of coronavirus disease 2019 (COVID-19) caused by the SARS-CoV-2 virus [1]. During the first 4 months of the year, transmission rates in Europe were of such a significant magnitude that several governments were forced to impose harsh lockdowns [2]. In the Netherlands, the first COVID-19 case was diagnosed on the 27th of February, and the government imposed a limited lockdown on the 23rd of March due to spiraling infection numbers. This lockdown led to closure of schools, daycares, and catering industry until the 11th of May and the 1st of June, respectively [3].

Lockdowns are serious interventions and are not expected to only have a specific effect on COVID-19 transmission but on all transmissible infectious diseases. This has been reported in similar situations in the past [4]. This effect may be especially pronounced in the field of pediatrics, as $28 \%$ of diagnoses in pediatric emergency departments (EDs) are attributed to infectious disease [5]. As expected, a decrease in the total numbers of pediatric admissions and visits to the emergency department (ED) has followed lockdowns worldwide [6-8]. However, it is unclear whether this reduction is solely due to a decrease in transmissible infections or also by behavioral changes around healthcare utilization. For example, there have been numerous reported examples of avoidance of care due to fear of a hospital environment, which is potentially disastrous [9-11].

Although the overall reduction in pediatric patients seeking care has been widely reported, stratification of specific disease groups has not been performed. If avoidance of care is a significant factor, one would expect a similar reduction in admissions and ED visits due to noninfectious disease compared to visits for transmissible infectious disease. Furthermore, lockdown as intervention allows for a unique opportunity to investigate the incidence of diagnoses that are assumed, but not definitively proven, to be related to or luxated by transmissible infections.

The aim of this study was to quantify the impact of the Dutch lockdown on pediatric clinical care in the Netherlands, to assess whether the impact can be attributed solely to a decrease in transmissible infections, and to critically review and summarize the international literature regarding the effect of lockdown on pediatric clinical care.

\section{Methods}

\section{Study design and ethics}

This was a retrospective multicenter study including 8 general hospitals in the Netherlands, mainly located in urban settings. None of the participating centers harbors a PICU. The study protocol was submitted to the medical ethics committee LDD (Leiden, the Netherlands), who judged that the protocol did not fall under the purview of the Dutch Law for Research with Human Subjects (WMO). The study was conducted in line with the general data protection regulation (GDPR).

\section{Data collection and aggregation}

Raw ED visit and admission data for each month between the 1st of January 2016 and the 30th of June 2020 were exported from the electronic patient records of each participating hospital. A filter was applied to exclude all subjects older than 18 years, admissions, ED visits on the surgery, or orthopedic service and admissions due to standard neonatal care. After merging the 8 datasets, a list of unique diagnoses was exported, and each individual diagnosis was allocated to one of the following 4 groups: communicable infections such as respiratory tract infections; infection-related, e.g., reactive arthritis; noncommunicable infections such as urinary tract 
infections; and noninfectious, for instance, failure to thrive. A list of the included diagnoses in each category can be found in Supplementary Table S1.

\section{Statistics}

The sum of ED visits and admissions per center for each individual month was calculated. Because of inter-center difference, data was normalized. The mean number of ED visits each month per center in 2016-2019 was calculated and fixed at $100 \%$, after which the relative percentage of admissions and ED visits during each month in 2016-2020 was calculated. A mixed effects model with month and year (2016-2019 vs 2020) as fixed effect and study center as random intercept was used to describe the relative reduction and $95 \%$ confidence interval (CI) in admissions and ED visits in 2020 for all diagnoses and for each diagnostic category separately. Bonferroni's method was used to adjust for multiple comparisons. Previous studies mention a substantial proportion of preventable ED visits in children which are due to nonurgent or trivial issues [12]. We therefore calculated the admission/ED ratio in order to estimate the acuity of ED visits. R-version 3.6.2 with the lme4 and ggeffects packages was used for statistical analysis.

\section{Literature review}

EMBASE, Medline Ovid, Web of Science Core Collection, and CINAHL EBSCOhost databases were searched for articles describing the effect of lockdown on pediatric clinic care (Supplementary Text S2). All study and publication types were included if they were published between January 1, 2020, and October 15, 2020 (date of the search), and contained any quantitative information on ED visits or hospitalization of children (0-18 years) during the COVID-19 pandemic. Studies that only described patient groups with specific diagnoses and/or COVID-19 or adult patients were excluded. Also, articles were excluded if the full text was not available or if it was written in another language than English. The selected articles were summarized in tables and arranged by country. The average reduction in ED visits per country was correlated with the maximum stringency of the lockdown measures during the first wave of COVID-19 (up until June 2020) [13].

\section{Results}

\section{General characteristics}

In total, 126,198 ED visits and 47,648 admissions were registered in the 8 participating centers between January 2016 and June 2020. During that period, $46 \%$ of ED visits and
$41 \%$ of admissions were due to communicable infections, and $37 \%$ of ED visits and $40 \%$ of admissions were related to noninfectious disease. In contrast, only $2.8 \%$ of ED visits and $2.9 \%$ of admissions were associated with noncommunicable infections. Of all patients, $70 \%$ were aged younger than 4 years old, 20\% were between 4 and 11 years old, and 10\% were 12 years or older.

\section{Effect of lockdown}

The estimated relative differences in ED visits and admissions between 2020 and 2016-2019 are displayed in Fig. 1a and f, respectively. A statistically significant reduction was observed from February 2020 onwards, the month in which the first COVID-19 patients were diagnosed. The largest contrast was observed in April 2020, the month after lockdown was imposed, when the estimated reduction was 59\% (95\% CI 51$68 \%, \mathrm{p}<0.001)$ for ED visits and $57 \%(95 \%$ CI $47-67 \%, p<$ 0.001 ) for admissions. Contrary to the number of visits, the mean ratio between admissions and ED visits was not different in 2020 compared to 2016-2019 (Supplementary Figure S3). The similar ratio of patients needing hospitalization suggests that the level of acuity did not change substantially during the national lockdown.

Stratification per disease group (Fig. 1b-e, g-j) showed that the largest reduction in both ED visits and admissions was observed in the communicable infections category. The estimated reduction in April was similar for ED visits $(76 \%$ (95\% CI 64-88\%, $p<0.001)$ and admissions (77\% $(95 \% \mathrm{CI}$ $63-92 \%, p<0.001)$. For diagnoses assumed to be related to infections, an identical reduction was observed, with a reduction of ED visits of $71 \%$ (95\% CI 54-89\%, $p<0.001)$ and reduction in admissions of $78 \%$ (95\%, CI 53-103\%, $p<$ $0.001)$. On the contrary, no significant effect on noncommunicable infections was observed. The largest reduction in noninfectious disease was found in April for ED visits (36\% reduction (95\% CI 26-46\%, $p<0.001$ ) and in March for admissions: $33 \%$ (95\% CI 20-46\%, $p<0.001$ ). Estimated effects per category for each individual month are displayed in Supplementary Table S4.

Finally, the effect of the lockdown ED visits and admissions related to respiratory infections, diabetes, and mental disease was estimated (Supplementary Figure S5).

\section{Review of the literature}

In total, 1.775 publications were screened for eligibility (Supplementary Figure 6), 33 of which reported the effect of COVID-19 or lockdown on emergency care utilization for general pediatrics. Most publications were from Italy $(n=12)[7$, 14-24] or from the USA $(n=8)$ [25-32]. An overview of the range of reported effects for individual countries is shown in Table 1. Three studies compared data of 2020 with the month(s) 


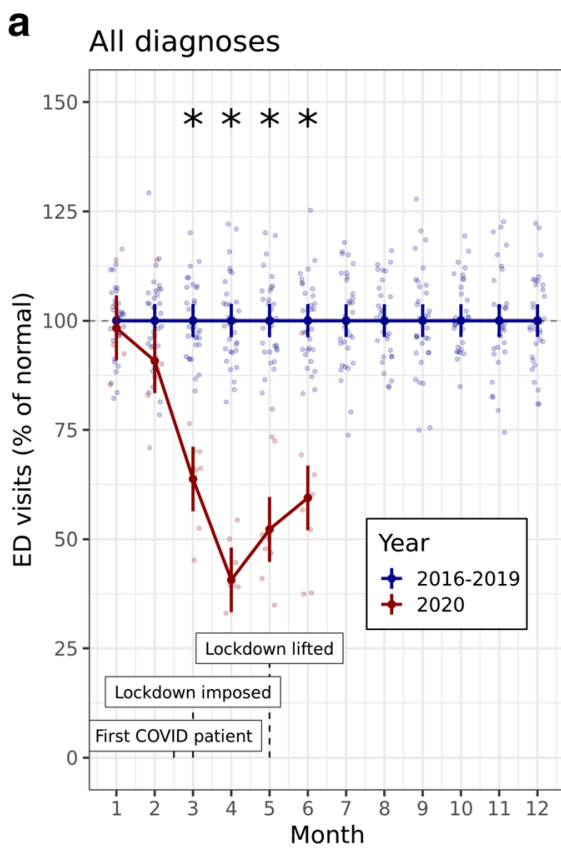

f

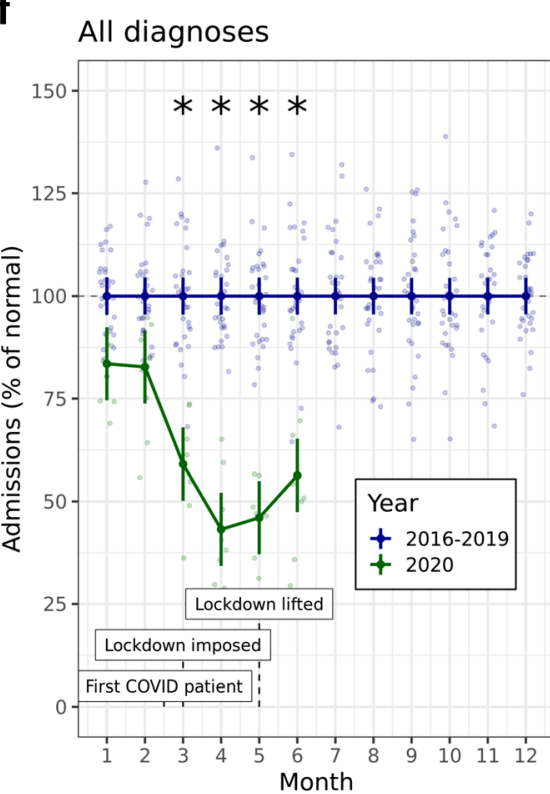

Fig. 1 Relative frequency of ED visits and ward admissions. Estimated effect of lockdown on ED visits (a-e) and pediatric hospital admissions $(\mathbf{f}-\mathbf{j})$. Blue lines indicate the average level during years 2016-2019 $(100 \%)$. The red line indicates the relative amount of ED visits for each month in 2020. The green line indicates that relative amount of hospital
ED visits
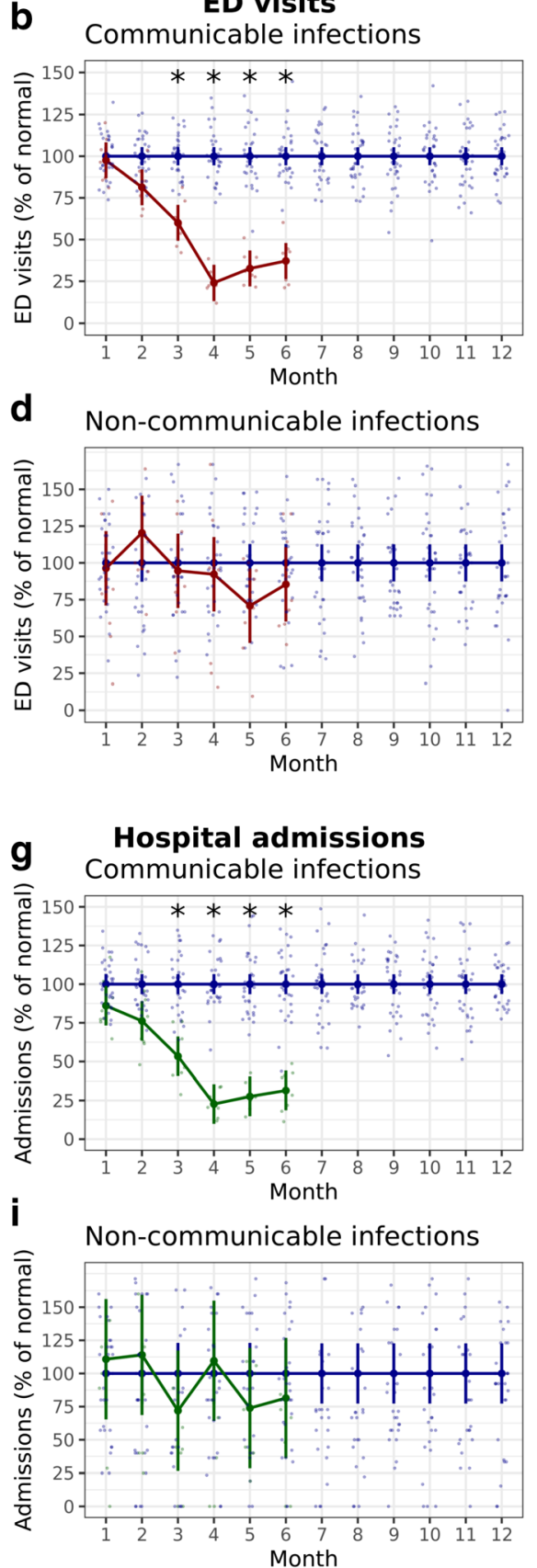

C Infection-related

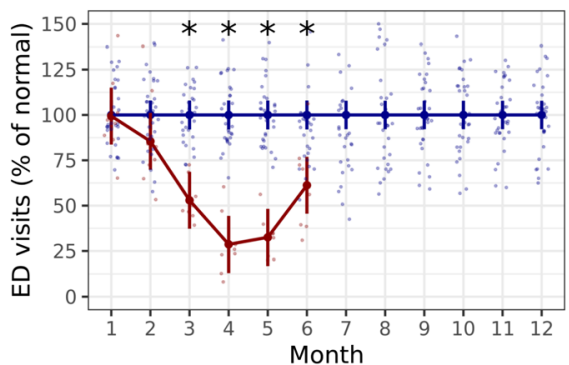

e Non-infectious



h
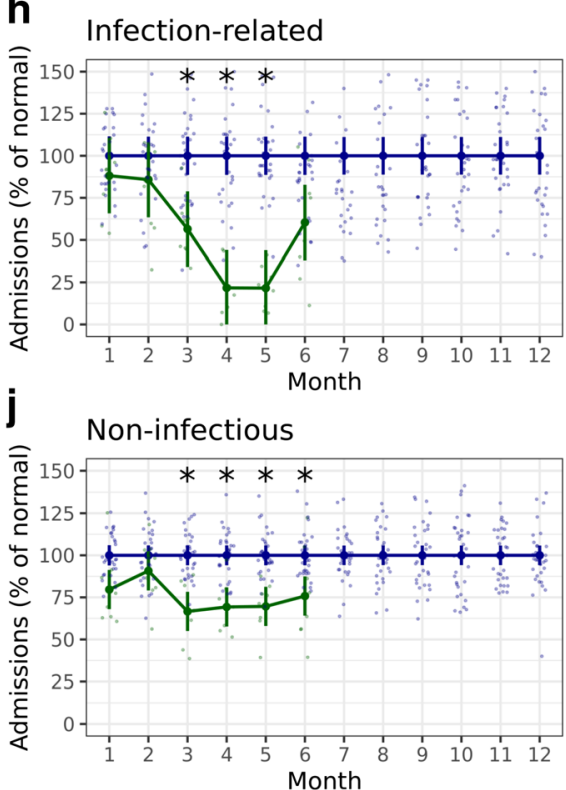

admissions for each month in 2020. Error bars represent the $95 \%$ confidence interval of the estimated marginal mean, and each dot is 1 month per hospital. The asterisk (*) indicates a significant difference between 2016 and 2020 ( $p<0.05$, after Bonferroni correction)

of children with non-acute illness or low triage codes was reported, causing a larger proportion of ED visits with higher acuity in most countries [14, 17, 20, 28, 35], although one Irish study reported no change after lockdown [36]. The absolute admission count during lockdowns decreased by $19-73 \%$ in all studies, except one [17]. The admission/ED visit ratio was reported to show an increase in Italy [14-19], Germany [37], and the USA 
Table 1 Overview of the effect of the COVID-19 pandemic on ED visits and hospitalization in general pediatrics compared to pre-COVID-19 periods

\begin{tabular}{|c|c|c|c|c|c|}
\hline Country & Reduction of ED visits & Increase in hospital admission/ED ratio & $\begin{array}{l}\text { Reduction of hospital } \\
\text { admissions }\end{array}$ & Reference & $\begin{array}{l}\text { Maximum stringency } \\
\text { of the lockdown } \\
\text { during the study period }\end{array}$ \\
\hline The Netherlands & $59 \%$ & Remained stable at $35-45 \%$ & $56 \%$ & Current study & 79.63 \\
\hline Italy & $62-88 \%$ & From $0.5-20$ to $0.9-41 \%$ & $\begin{array}{l}31-71 \% ; 19 \% \text { increase } \\
\text { in one hospital }\end{array}$ & {$[7,14-24]^{\#}$} & 93.52 \\
\hline Spain & $65 \%$ & - & - & {$[35]$} & 85.19 \\
\hline Germany & $64 \%$ & From 14 to $27 \%$ & $38 \%$ & {$[37]$} & 76.85 \\
\hline France & $68 \%$ & - & $45 \%$ & {$[40]$} & 87.96 \\
\hline Austria & $83 \%$ & - & - & {$[53]$} & 81.48 \\
\hline UK & $30-66 \% *$ & - & - & {$[6,54]$} & 79.63 \\
\hline Ireland & $46-54 \%$ & Remained stable (14-15\%) & $41-54 \%$ & {$[36,38]$} & 90.74 \\
\hline Finland & $65-65 \%$ & - & $45-60 \%$ & {$[33]^{\#}$} & 67.59 \\
\hline South Africa & $58 \%$ & - & - & {$[41]$} & 87.96 \\
\hline Morocco & $74 \%$ & - & $42 \%$ & {$[55]$} & 93.52 \\
\hline USA & $48-87 \%$ & From $19-20$ to $22-24 \%$ & $73 \%$ & [25-32] & 72.69 \\
\hline Argentina & $89 \%$ & - & - & {$[34]$} & 100 \\
\hline Australia & $47 \%$ & - & - & {$[52]$} & 73.15 \\
\hline
\end{tabular}

* Isba et al. [6] reported data from March, whereas lockdown was issued only after March 23, 2020

\# Vierucci et al. [21], Ciofi Degli et al. [22], and Kuitunen et al. [33] compared data with the period before lockdown/behavioral measures, instead of the previous year(s)

${ }^{\$}$ Data from Walker et al. [32] was based on a questionnaire among healthcare professionals

${ }^{\dagger}$ Government Response Stringency Index (range 0 to 100,100 is strictest) [13]

[26, 28], but not in Ireland [38]. There was no correlation between the reduction in $\mathrm{ED}$ visits and the maximum stringency during the study period $(R=0.46, p=0.098$, Supplementary Figure S7).

\section{Discussion}

Emergency department visits and hospital admissions were impressively decreased during COVID-19 lockdowns, especially for children with communicable infections. When determining the reason for the observed effects, we expect that three separate caused have played some part in the observed reduction in clinical visits.

First, the closure of school and daycares led to an immediate and dramatic decrease in contacts between children and, as a result, in transmissible infections, which are the cause of a large proportion of pediatric healthcare visits. The current study supports this hypothesis, as the largest observed reduction in ED visits and admissions was found for transmissible infections and infection-related diagnoses. If this reduction could not be attributed to this effect, a reduction of similar size would be expected in the other categories as well. This factor could be considered a positive consequence of a lockdown, which may have led to a decrease in morbidity and healthcare costs. The number of children visiting the ED because of a respiratory illness was reduced more compared to other pediatric diagnoses in other countries as well. Hartnett et al. reported that the largest declines in the number of ED visits were seen in children aged $\leq 10$ years for respiratory symptoms (78\%), viral infections (79\%), influenza (97\%), and otitis (85\%) [39]. A large time series analysis in France also reported a $70 \%$ reduction for the common cold, otitis media, and gastro-enteritis. In this study, visits because of urinary tract infections (UTIs) were not affected, and UTI admissions even increased by $21 \%$, which is in line with our findings [40]. Furthermore, several Italian hospitals saw a decline of 60 $96 \%$ for presentations because of fever and respiratory or other infections [18-23]. Other countries reported a decrease in respiratory infections between 52 and $98 \%$ as well, and this reduction was generally larger than for other diagnosis groups $[8,33,36,37,41,42]$, except for two studies in Spain, a country with a harsh lockdown [13]. Here, the reduction in the number of ED visits because of respiratory symptoms was identical to the overall reduction in visits $[16,35]$. In addition to reduced ED visits, our data also showed a decrease in infection-related hospitalizations, which was also observed in Denmark [43].

A second factor of influence could have been the fact that the pandemic led to an extreme demand on the healthcare sector and that clinical care in the hospital largely revolved around COVID-19 patients. Fear of SARS-CoV-2 infection 
and a desire to not raise demand on the healthcare sector even further may have caused parents to refrain from going to the hospital with their children, despite worsening symptoms [44]. In that case, a reduction in noncommunicable infections and noninfectious diagnoses would be expected. Our data indicates a significant decrease in clinical care related to noninfectious diagnoses, although the reduction was less compared nontransmissible infections. Interestingly, the ratio between admissions and ED visits remained constant in 2020 compared to 2016-2019. If avoidance of care would lead to more children with high acuity illness due to delayed presentation to the ED, this ratio would be expected to rise compared to the previous years. The fact that this was not the case gives reassurance that the avoidance of care did not lead to adverse consequences on a large scale in the Netherlands. However, we did not take disease severity or length of stay into account in our analyses, and more than 50 anecdotal reports regarding collateral harm due to delayed presentation were reported in the Netherlands [45]. However, several countries reported a higher admission/ED visit ratio, and studies that analyzed triage codes found that overall reasons for the ED visit were associated with a higher acuity of disease [28, 41, 46]. Furthermore, there is ample international evidence that point to adverse consequences due to care avoidance. For example, although Dayal et al. reported a $75 \%$ reduction in the number of new diabetes cases during lockdown, the authors described three patients who have been diagnosed during lockdown and suffered from severe diabetic keto-acidosis, in which parents declared they delayed seeking care due to COVID-19 circumstances [47].

Third, it is possible that parents and other caregivers experienced less pressure than usual to seek prompt clinical care for their children in the event of illness. During lockdown, working from home was mandatory and childcare was necessarily combined with professional activities. Additionally, reduced external feedback regarding health from schoolteachers, daycare workers, or grandparents could also lead to a reduced extrinsic motivation to visit the ED [48]. Some evidence of this effect could be derived from the current analysis, since numbers of noninfectious diagnoses were also reduced. However, it is not possible to completely isolate this effect from the avoidance of care that is assumed to be a factor as well.

The dramatic decrease in transmissible infectious diseases leads to an opportunity to study the incidence of diagnoses that are assumed but not definitely proven to be caused by infections. While the base of circumstantial evidence to this effect is broad, the current analysis further adds to this. The relative reduction in assumed infection-related diagnoses was as large as the reduction for communicable infections. Our review of the literature found that similar reductions in pediatric healthcare utilization have been reported worldwide (Table 1). Besides general effects on the total volume of pediatric care, several studies reported on the effect of lockdown for individual diagnoses. For example, ED visits because of asthma decreased by $76-84 \%$ [30, 39], and Tacquechel et al. reported a $87 \%$ decrease in daily outpatient visits due to asthma and an $84 \%$ decrease in hospital visits (ED and inpatient) [49]. Shifts in the incidence of diagnoses in other specialties were also reported. For example, hospital admissions to a dermatology department in Poland reduced by $85 \%$ [50]. Finally, it is important to note that the pandemic and the accompanying lockdowns may also exhibit negative effects on mental health. For example, a $25 \%$ increase in diagnoses related to mental health and a $104 \%$ increase in admissions due to anorexia nervosa have been reported [51, 52]. On the other hand, a 27\% reduction in mental health-related diagnoses as reason for ED visits was reported in Ireland [36]. The reduction in healthcare utilization was comparable to many other countries, despite the limited lockdown imposed in the Netherlands.

Our study has several limitations. First, since noncommunicable infections were a relatively small percentage of total diagnoses and as a result, the effect of lockdown on this category was difficult to estimate. Second, data on the level of ED acuity, length of hospital admission, and ICU admissions could have provided additional insights but were not available. Furthermore, due to different electronic management systems in each hospital, data exports were conducted individually for each study center. Although the requested data was specific, this may have led to small numbers of diagnoses that have been missed.

Strengths of this study include the multicenter approach, which makes this one of the most comprehensive analyses to date, allowed for the use of a mixed effects model and for the precise estimation of the average effects of lockdown in the Netherlands. Furthermore, the stratification of diagnoses in four categories gives a better overview of the specific effects of lockdown on the propensity of parents and children to go to the hospital during lockdowns. Future analyses may replicate the current findings but should also focus on the acuity of the clinical presentations and the proportion of delayed diagnoses or treatment.

\section{Conclusion}

The COVID-19 pandemic and associated lockdowns caused a significant decrease in pediatric ED visits and hospital admissions in both the Netherlands as the rest of the world. While a large proportion of the reduction can be attributed to a decrease in transmissible infections not caused by SARS-CoV2, our analyses show that avoidance of care could be a factor as well. Pediatricians should be aware of this possibility in the event of future lockdowns in their countries. 
Abbreviations CI, Confidence interval; COVID-19, Coronavirus disease 2019; ED, Emergency department; PED, Pediatric emergency department; UTI, Urinary tract infection

Supplementary Information The online version contains supplementary material available at https://doi.org/10.1007/s00431-021-04015-0.

Acknowledgements The authors wish to thank n.n. from the Erasmus MC Medical Library for developing and updating the search strategies, as well as the data officers who retrieved the data from each individual hospital.

Code availability Data is available from the corresponding author upon reasonable request.

Authors' contributions MK designed the study, analyzed the data, and wrote the manuscript.

DP designed the study, performed the literature review, supported data analysis, and wrote the manuscript.

MV coordinated the data retrieval process, provided input during the analysis, and reviewed the manuscript.

MH coordinated the data retrieval process, provided input during the analysis, and reviewed the manuscript.

JW coordinated the data retrieval process, provided input during the analysis, and reviewed the manuscript.

$\mathrm{JN}$ coordinated the data retrieval process, provided input during the analysis, and reviewed the manuscript.

JBE coordinated the data retrieval process, provided input during the analysis, and reviewed the manuscript.

GT coordinated the data retrieval process, provided input during the analysis, and reviewed the manuscript.

$\mathrm{NV}$ coordinated the data retrieval process, provided input during the analysis, and reviewed the manuscript.

GJD designed and supervised the study and wrote the manuscript.

Funding This study was financially supported by the Elisabeth von Freyburg Stichting.

Data Availability All data presented in this manuscript is available from the corresponding author upon reasonable request.

\section{Declarations}

Ethics approval The study protocol was submitted to the medical ethics committee LDD (Leiden, the Netherlands), who judged that the protocol did not fall under the purview of the Dutch Law for Research with Human Subjects (WMO).

Consent to participate Informed consent was waived by the Institutional Review Boards because all data was collected anonymously.

\section{Consent for publication N/A}

Conflict of interest The authors declare no competing interests.

Open Access This article is licensed under a Creative Commons Attribution 4.0 International License, which permits use, sharing, adaptation, distribution and reproduction in any medium or format, as long as you give appropriate credit to the original author(s) and the source, provide a link to the Creative Commons licence, and indicate if changes were made. The images or other third party material in this article are included in the article's Creative Commons licence, unless indicated otherwise in a credit line to the material. If material is not included in the article's Creative Commons licence and your intended use is not permitted by statutory regulation or exceeds the permitted use, you will need to obtain permission directly from the copyright holder. To view a copy of this licence, visit http://creativecommons.org/licenses/by/4.0/.

\section{References}

1. World Health Organization. Coronavirus disease 2019 (COVID19). Situation Report - 51. Published March 112020

2. Alfano V, Ercolano S (2020) The efficacy of lockdown against COVID-19: a cross-country panel analysis. Appl Health Econ Health Policy 18(4):509-517. https://doi.org/10.1007/s40258020-00596-3

3. News items on Coronavirus COVID-19 by the Government of the Netherlands. Retrieved from https://www.government.nl/topics/ coronavirus-covid-19/news

4. Thelot B, Bourrillon A (1996) Coincidence of public transport strike with bronchiolitis epidemic. Lancet 348(9043):1743-1744. https://doi.org/10.1016/S0140-6736(05)65879-5

5. Hasegawa K, Tsugawa Y, Cohen A, Camargo CA Jr (2015) Infectious disease-related emergency department visits among children in the US. Pediatr Infect Dis J 34(7):681-685. https://doi.org/ 10.1097/INF.0000000000000704

6. Isba R, Edge R, Jenner R, Broughton E, Francis N, Butler J (2020) Where have all the children gone? Decreases in paediatric emergency department attendances at the start of the COVID-19 pandemic of 2020. Arch Dis Child. https://doi.org/10.1136/ archdischild-2020-319385

7. Lazzerini M, Barbi E, Apicella A, Marchetti F, Cardinale F, Trobia $\mathrm{G}$ (2020) Delayed access or provision of care in Italy resulting from fear of COVID-19. Lancet Child Adolesc Health 4(5):e10-e11. https://doi.org/10.1016/s2352-4642(20)30108-5

8. Friedrich F, Ongaratto R, Scotta MC, Veras TN, Stein R, Lumertz MS, Jones MH, Comaru T, Pinto LA (2020) Early Impact of social distancing in response to COVID-19 on hospitalizations for acute bronchiolitis in infants in Brazil. Clin Infect Dis. https://doi.org/10. 1093/cid/ciaa1458

9. Snapiri O, Rosenberg Danziger C, Krause I, Kravarusic D, Yulevich A, Balla U, Bilavsky E (2020) Delayed diagnosis of paediatric appendicitis during the COVID-19 pandemic. Acta Paediatr Int J Paediatr 109(8):1672-1676. https://doi.org/10.1111/ apa. 15376

10. Catassi GN, Vallorani M, Cerioni F, Lionetti E, Catassi C (2020) A negative fallout of COVID-19 lockdown in Italy: life-threatening delay in the diagnosis of celiac disease. Dig Liver Dis 52(10):10921093. https://doi.org/10.1016/j.dld.2020.05.016

11. Chiaravalli S, Ferrari A, Sironi G, Gattuso G, Bergamaschi L, Puma N, Schiavello E, Biassoni V, Podda M, Meazza C, Spreafico F, Casanova M, Terenziani M, Luksch R, Massimino M (2020) A collateral effect of the COVID-19 pandemic: delayed diagnosis in pediatric solid tumors. Pediatr Blood Cancer:e28640. https://doi. org $/ 10.1002 /$ pbc. 28640

12. Brandenberger J, Bozorgmehr K, Vogt F, Tylleskar T, Ritz N (2020) Preventable admissions and emergency-department-visits in pediatric asylum-seeking and non-asylum-seeking patients. Int J Equity Health 19(1):58. https://doi.org/10.1186/s12939-02001172-w

13. Hale T, Angrist N, Cameron-Blake E, Hallas L, Kira B, Majumdar S, Petherick A, Phillips T, Tatlow H, Webster S (2020) Oxford COVID-19 government response tracker, Blavatnik School of Government.Accessed February 19, 2021. https://www.bsg.ox.ac. $\mathrm{uk} /$ research/research-projects/coronavirus-government-responsetracker 
14. Clavenna A, Nardelli S, Sala D, Fontana M, Biondi A, Bonati M (2020) Impact of COVID-19 on the pattern of access to a pediatric emergency department in the Lombardy Region, Italy. Pediatr Emerg Care 36:e597-e598. https://doi.org/10.1097/pec. 0000000000002232

15. Masetti R, Corsini I, Leardini D, Lanari M, Pession A (2020) Presentations to the emergency department in Bologna, Italy, during COVID-19 outbreak. BMJ Paediatr Open 4 (1). https://doi.org/ 10.1136/bmjpo-2020-000748

16. Valitutti F, Zenzeri L, Mauro A, Pacifico R, Borrelli M, Muzzica S, Boccia G, Tipo V, Vajro P (2020) Effect of population lockdown on pediatric emergency room demands in the era of COVID-19. Front Pediatr 8. https://doi.org/10.3389/fped.2020.00521

17. Scaramuzza A, Tagliaferri F, Bonetti L, Soliani M, Morotti F, Bellone S, Cavalli C, Rabbone I (2020) Changing admission patterns in paediatric emergency departments during the COVID-19 pandemic. Arch Dis Child. https://doi.org/10.1136/archdischild2020-319397

18. Cozzi G, Zanchi C, Giangreco M, Rabach I, Calligaris L, Giorgi R, Conte M, Moressa V, Delise A, Poropat F (2020) The impact of the COVID-19 lockdown in Italy on a pediatric emergency setting. Acta Paediatr 109:2157-2159. https://doi.org/10.1111/apa.15454

19. Manzoni P, Militello MA, Fiorica L, Cappiello AR, Manzionna M (2020) Impact of COVID-19 epidemics in paediatric morbidity and utilisation of Hospital Paediatric Services in Italy. Acta Paediatr. https://doi.org/10.1111/apa.15435

20. Ciacchini B, Tonioli F, Marciano C, Faticato MG, Borali E, Pini Prato A, Felici E (2020) Reluctance to seek pediatric care during the COVID-19 pandemic and the risks of delayed diagnosis. Ital $\mathrm{J}$ Pediatr 46(1):87. https://doi.org/10.1186/s13052-020-00849-w

21. Vierucci F, Bacci C, Mucaria C, Dini F, Federico G, Maielli M, Vaccaro A (2020) How COVID-19 pandemic changed children and adolescents use of the emergency department: the experience of a secondary care pediatric unit in Central Italy. SN Compr Clin Med 2:1959-1969. https://doi.org/10.1007/s42399-020-00532-5

22. Ciofi Degli Atti ML, Campana A, Muda AO, Concato C, Ravà L, Ricotta L, Reale A, Barbieri M, D'Argenio P, Lancella L, Villani A, Raponi M (2020) Facing SARS-CoV-2 pandemic at a COVID-19 Regional Children's Hospital in Italy. Pediatr Infect Dis J 39:e221e225. https://doi.org/10.1097/inf.0000000000002811

23. Iozzi L, Brambilla I, Foiadelli T, Marseglia GL, Ciprandi G (2020) Paediatric emergency department visits fell by more than $70 \%$ during the COVID-19 lockdown in Northern Italy. Acta Paediatr Int J Paediatr 109:2137-2138. https://doi.org/10.1111/apa.15458

24. Agostoni C, Bertolozzi G, Cantoni B, Colombo C, Montini G, Marchisio P (2020) Three months of COVID-19 in a pediatric setting in the center of Milan. Pediatr Res. https://doi.org/10.1038/ s41390-020-01108-8

25. Dean P, Zhang Y, Frey M, Shah A, Edmunds K, Boyd S, Schwartz H, Frey T, Stalets E, Schaffzin J, Vukovic AA, Reeves S, Masur T, Kerrey B (2020) The impact of public health interventions on critical illness in the pediatric emergency department during the SARSCoV-2 pandemic

26. Even L, Lipshaw MJ, Wilson PM, Dean P, Kerrey BT, Vukovic AA (2020) Pediatric emergency department volumes and throughput during the COVID-19 pandemic

27. Westgard BC, Morgan MW, Vazquez-Benitez G, Erickson LO, Zwank MD (2020) An analysis of changes in emergency department visits after a state declaration during the time of COVID-19. Ann Emerg Med 76:595-601. https://doi.org/10.1016/j. annemergmed.2020.06.019

28. Chaiyachati BH, Agawu A, Zorc JJ, Balamuth F (2020) Trends in pediatric emergency department utilization after institution of COVID-19 mandatory social distancing. J Pediatr 226:274277.e1. https://doi.org/10.1016/j.jpeds.2020.07.048
29. Hartford EA, Keilman A, Yoshida H, Migita R, Chang T, Enriquez B, Liu DR (2020) Pediatric emergency department responses to COVID-19: transitioning from surge preparation to regional support. Disaster Med Public Health Prep:1-14. https://doi.org/10. 1017/dmp.2020.197

30. Kenyon CC, Hill DA, Henrickson SE, Bryant-Stephens TC, Zorc JJ (2020) Initial effects of the COVID-19 pandemic on pediatric asthma emergency department utilization. J Allergy Clin Immunol Pract 8:2774-2776.e1. https://doi.org/10.1016/j.jaip.2020.05.045

31. Hassoun A, Pugh S, Merced I, Sharma M (2020) The power of social isolation on pediatric emergency visits during COVID-19 lockdown. Acta Paediatr 109:2425-2426. https://doi.org/10.1111/ apa. 15490

32. Walker DM, Tolentino VR (2020) COVID-19: the effects on the practice of pediatric emergency medicine. Pediatr Emerg Med Pract 17(3):1-15

33. Kuitunen I, Artama M, Mäkelä L, Backman K, Heiskanen-Kosma T, Renko M (2020) Effect of social distancing due to the COVID19 pandemic on the incidence of viral respiratory tract infections in children in Finland during early 2020. Pediatr Infect Dis J 39:e423e427. https://doi.org/10.1097/inf.0000000000002845

34. Ferrero F, Ossorio MF, Torres FA, Debaisi G (2020) Impact of the COVID-19 pandemic in the paediatric emergency department attendances in Argentina. Arch Dis Child 106:e5. https://doi.org/10. 1136/archdischild-2020-319833

35. Molina Gutiérrez MÁ, Ruiz Domínguez JA, Bueno Barriocanal M, de Miguel LB, López López R, Martín Sánchez J, de Ceano-Vivas la Calle M (2020) Impact of the COVID-19 pandemic on emergency department: early findings from a hospital in Madrid. An Pediatr 93:313-322. https://doi.org/10.1016/j.anpedi.2020.06.021

36. Dann L, Fitzsimons J, Gorman KM, Gorman KM, Hourihane J, Hourihane J, Okafor I (2020) Disappearing act: COVID-19 and paediatric emergency department attendances. Arch Dis Child 105:810-811. https://doi.org/10.1136/archdischild-2020-319654

37. Dopfer C, Wetzke M, Zychlinsky Scharff A, Mueller F, Dressler F, Baumann U, Sasse M, Hansen G, Jablonka A, Happle C (2020) COVID-19 related reduction in pediatric emergency healthcare utilization - a concerning trend. BMC Pediatr 20(1):427. https://doi. org/10.1186/s12887-020-02303-6

38. McDonnell T, Nicholson E, Conlon C, Barrett M, Cummins F, Hensey C, McAuliffe E (2020) Assessing the impact of COVID19 public health stages on paediatric emergency attendance. Int $\mathrm{J}$ Environ Res Public Health 17(18):1-25. https://doi.org/10.3390/ ijerph17186719

39. Hartnett KP, Kite-Powell A, DeVies J, Coletta MA, Boehmer TK, Adjemian J, Gundlapalli AV (2020) Impact of the COVID-19 Pandemic on Emergency Department Visits - United States, January 1, 2019-May 30, 2020. MMWR Morb Mortal Wkly Rep 69(23):699-704. https://doi.org/10.15585/mmwr.mm6923e1

40. Angoulvant F, Ouldali N, Yang DD, Filser M, Gajdos V, Rybak A, Guedj R, Soussan-Banini V, Basmaci R, Lefevre-Utile A, BrunNey D, Beaujouan L, Skurnik D (2020) COVID-19 pandemic: impact caused by school closure and national lockdown on pediatric visits and admissions for viral and non-viral infections, a time series analysis. Clin Infect Dis 72:319-322. https://doi.org/10.1093/ $\mathrm{cid} / \mathrm{ciaa} 710$

41. Akuaake LM, Hendrikse C, Spittal G, Evans K, Van Hoving DJ (2020) Cross-sectional study of paediatric case mix presenting to an emergency centre in Cape Town, South Africa, during COVID-19. BMJ Paediatr Open 4 (1). https://doi.org/10.1136/bmjpo-2020000801

42. Krivec U, Kofol Seliger A, Tursic J (2020) COVID-19 lockdown dropped the rate of paediatric asthma admissions. Arch Dis Child 105:809-810. https://doi.org/10.1136/archdischild-2020-319522

43. Polcwiartek LB, Polcwiartek C, Andersen MP, Ostergaard L, Broccia MD, Gislason GH, Kober L, Torp-Pedersen C, Schou M, 
Fosbol E, Kragholm K, Hagstrom S (2021) Consequences of coronavirus disease-2019 (COVID-19) lockdown on infection-related hospitalizations among the pediatric population in Denmark. Eur $\mathrm{J}$ Pediatr. https://doi.org/10.1007/s00431-021-03934-2

44. Malhotra C, Chaudhry I, Ozdemir S, Finkelstein EA Reduced health-care utilization among people with chronic medical conditions during coronavirus disease 2019. Proceedings of Singapore Healthcare 0 (0):2010105820964533. https://doi.org/10.1177/ 2010105820964533

45. Jansen D, Illy KE (2020) Delayed presentation to regular Dutch paediatric care in COVID-19 times: a national survey. BMJ Paediatr Open 4(1):e000834. https://doi.org/10.1136/bmjpo-2020000834

46. Goldman RD, Grafstein E, Barclay N, Irvine MA, PortalesCasamar E (2020) Paediatric patients seen in 18 emergency departments during the COVID-19 pandemic. Emerg Med J 37(12):773777. https://doi.org/10.1136/emermed-2020-210273

47. Dayal D, Gupta S, Raithatha D, Jayashree M (2020) Missing during COVID-19 lockdown: children with onset of type 1 diabetes. Acta Paediatr Int J Paediatr 109(10):2144-2146. https://doi.org/10.1111/ apa. 15443

48. Kubicek K, Liu D, Beaudin C, Supan J, Weiss G, Lu Y, Kipke MD (2012) A profile of nonurgent emergency department use in an urban pediatric hospital. Pediatr Emerg Care 28(10):977-984. https://doi.org/10.1097/PEC.0b013e31826c9aab

49. Taquechel K, Diwadkar AR, Sayed S, Dudley JW, Grundmeier RW, Kenyon CC, Henrickson SE, Himes BE, Hill DA (2020) pediatric asthma health care utilization, viral testing, and air pollution changes during the COVID-19 pandemic. J Allergy Clin Immunol Pract. https://doi.org/10.1016/j.jaip.2020.07.057
50. Białynicki-Birula R, Siemasz I, Otlewska A, Matusiak Ł, Szepietowski JC (2020) Influence of COVID-19 pandemic on hospitalizations at the tertiary dermatology department in south-west Poland. Dermatol Ther 33:e13738. https://doi.org/10.1111/dth. 13738

51. Haripersad YV, Kannegiesser-Bailey M, Morton K, Skeldon S, Shipton N, Edwards K, Newton R, Newell A, Stevenson PG, Martin AC (2020) Outbreak of anorexia nervosa admissions during the COVID-19 pandemic. Arch Dis Child 106:e15. https://doi.org/ 10.1136/archdischild-2020-319868

52. Cheek JA, Craig SS, West A, Lewena S, Hiscock H (2020) Emergency department utilisation by vulnerable paediatric populations during COVID-19 pandemic. Emerg Med Australas 32:870 871. https://doi.org/10.1111/1742-6723.13598

53. Schaffert M, Zimmermann F, Bauer L, Kastner S, Schwarz A, Strenger V, Metzger R, Thun-Hohenstein L, Sperl W, Weghuber $\mathrm{D}$, Wortmann SB, additional individual contributors as listed in the s (2020) Austrian study shows that delays in accessing acute paediatric healthcare outweighed the risks of COVID-19

54. Hughes HE, Hughes TC, Morbey R, Challen K, Oliver I, Smith GE, Elliot AJ (2020) Emergency department use during COVID-19 as described by syndromic surveillance. Emerg Med J 37:600-604. https://oi.org/10.1136/emermed-2020-209980

55. Mekaoui N, Razine R, Bassat Q, Benjelloun BS, Karboubi L (2020) The effect of COVID-19 on paediatric emergencies and admissions in Morocco: cannot see the forest for the trees?

Publisher's note Springer Nature remains neutral with regard to jurisdictional claims in published maps and institutional affiliations.

\section{Affiliations}

\section{Matthijs D. Kruizinga ${ }^{1,2}$ (D) Daphne Peeters ${ }^{1} \cdot$ Mirjam van Veen ${ }^{3} \cdot$ Marlies van Houten $^{4} \cdot$ Jantien Wieringa $^{5} \cdot$ Jeroen G. Noordzij ${ }^{6}$. Jolita Bekhof ${ }^{7} \cdot$ Gerdien Tramper-Stranders $^{8} \cdot$ Nienke J. Vet ${ }^{9} \cdot$ Gertjan J. A. Driessen $^{1,10}$}

1 Juliana Children's Hospital (Haga Teaching hospital), Els BorstEilersplein 275, 2545 AA The Hague, the Netherlands

2 Centre for Human Drug Research, Leiden, the Netherlands

3 Department of Pediatrics, Groene Hart Ziekenhuis, Gouda, the Netherlands

4 Department of Pediatrics, Spaarne Gasthuis, Hoofddorp/ Haarlem, the Netherlands

5 Department of Pediatrics, Haaglanden Medical Centre, The Hague, the Netherlands
6 Department of Pediatrics, Reinier de Graaf Ziekenhuis, Delft, the Netherlands

7 Department of Pediatrics, Isala, Zwolle, the Netherlands

8 Department of Pediatrics, Franciscus Gasthuis\& Vlietland, Rotterdam, the Netherlands

9 Department of Pediatrics, St Antonius Ziekenhuis, Nieuwegein, the Netherlands

10 Department of Pediatrics, Maastricht University Medical Center, Maastricht, the Netherlands 